\title{
Impact of Sales Promotions and Advertising Techniques on Consumer Behaviour
}

\author{
Dr. Niveen Mohamed El Saghier*
}

(*) Dr. Niveen Mohamed El Saghier, Lecturer, College of Management and Technology, Arab Academy for science, Technology and Maritime Transport, E-mail: niveenmohamed@yahoo.com 


\section{Abstract}

The current research aims to investigate the most frequently used tools of sales promotion in retail sector in Egypt, such as: coupons, discount and buy one get one free. It also aims at testing the impact of different sales promotion tools on Consumer Buying Behaviour. Moreover, the paper aims at exploring the importance of different advertising techniques, which are; Attention, Interest, Desire, Action. In addition, the research will test if applying AIDA model of advertisement will enhance the buying behaviour of the customer or not. A regression analysis and structural Equation Modelling (SEM) are constructed to test the direct impact of sales promotion tools as well as AIDA model to have better consumer buying behaviour. Results show that all sales promotion activities have a significant impact on Consumer buying behaviour. Also, Buy one get one free is the most attractive promotional tool, then comes price discounts, while coupons show the least significance on Consumer buying behaviour. In addition, it was found that all advertising techniques are significantly changing the consumer buying behaviour in the retail sector in Egypt except Interest which shows an insignificant impact on Consumer buying behaviour.

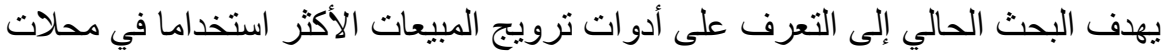

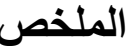

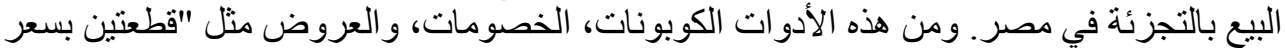

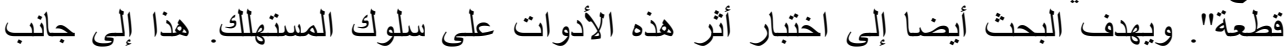

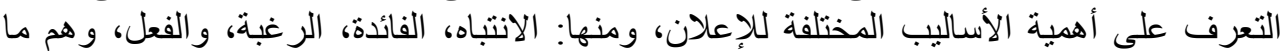
يندرجوا تحت عنوان نموذج "AIDA". وبالتالي، يهدف البحث اختبار مدى أثر تطبيق نموذج الأب "AIDA" وقد قام الباحث بتكوين نموذجي الانحدار و المعادلة الهيكلية "SEM"،واللذان أثبتا أن هناك أثن

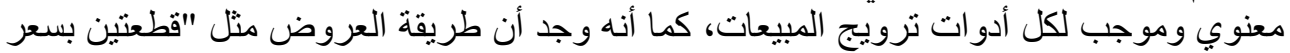

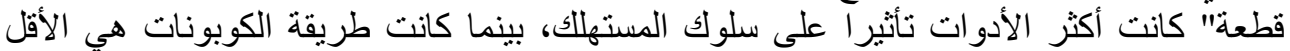
تأثير ا. وفيما يخص طرة كرن الاعلان، فقد وجد أن كل الطرق لها أثر معنوي فيما عدا طريقة الفائدة و التي لم يثبت لها أي أثر معنوي على سلوف الث الثراء لدى الدى المستهلك. 


\section{Introduction}

Sales promotion became a vital tool for products and services marketing. Its importance is increasing significantly during time, as one of its aims is to directly influence the purchase behaviour of organization consumers. Another aim is that sales promotions are highly effective in exposing consumers to products for the first time and can serve as key promotional components in the early stages of new product presentation. Thus, organizations have to reconsider the relationship between attitude and behaviour of their consumers.

Moreover, advertising is an effective source of changing the consumer mind towards a particular product or service (Katke, 2007). Advertising plays an important role in presenting organizations business, as well as attracting customers. It is considered as one of the promotional mix components to create consumer awareness. Nowadays, advertising have become one of the crucial commercial activities in competitive business environment.

One can view advertising as a form of promotion, which is considered as one of the four pillars or main principals of marketing (along with product, place, and price). In other words, promotion encompasses the techniques that the advertiser uses to communicate with current and potential consumers. The type of promotions that the organization is supposed to use depends on several things. Advertisers create advertisements with a variety of objectives in mind from getting people to sample a product, to donate money for an environmental cause. Advertisement is a good way to create the need or desire in the people who view, read or listen to them. Once the advertising objectives have been decided, the creative advertising team must decide how to present the product to be able to transfer a certain message and to have the maximum impact of it on the target market.

After the current introduction, the next section will identify the problem statements. Section four will present all of the related previous studies regarding promotional tools, as the independent variables, including; coupons, discount and buy one get one free, and consumers buying behaviour, as the dependent variable, as well as presenting the AIDA model dimensions as mediating the mentioned relationship. Section five will build a theoretical framework and hypotheses. Section six will present findings analysis and finally study conclusion and recommendations in section seven. 


\section{Problem statement}

Competition in the retail sector in Egypt has become rapidly increasing nowadays. This competition imposes a great challenge on companies working in such a field and forces them to search for new ideas that could be able to give them a competitive advantage.

It was found that the retail stores in Egypt are facing a great challenge in selling their products and services. Thus, it was critical to define factors that influence consumer buying behavior to be able to advice the retails stores in Egypt to use them.

Checking literature, the usage of sales and advertising promotions tools were found to be important activities which increase consumer buying behavior if the retails stores are able to provide them correctly. Thus, it is so important to evaluate different sales promotions as well as various advertising techniques and their impact on the consumer behavior to be able to make a recommendation of using such tools in the field of retails.

\section{Research Objectives}

The aim of this paper is to:

1. Investigate the various promotion tools

2. Examine the impact of different sales promotion tools, representing one group of the independent variables, which are: coupons, discount and buy one get one free on consumer buying behaviour, representing the dependent variable towards market retailers.

3. Explore various advertising techniques, which are: Attention, Interest, Desire, Action, representing another group of the independent variables.

\section{Literature Review}

\subsection{Sales Promotion}

Promotion is one of the key factors in the marketing mix, as it plays an important role in market success. So, Promotions deals with the entire set of activities, which communicate the product, brand or service to the user. The whole idea of promotion is to make people aware of the product and 
attract the audience in preference over others. Promotion is defined as a technique that is used by marketer on a temporary basis to create attractive products and services which encourage the customers to purchase them in a specific time period by providing more benefits (Mercer, 2002).

Promotion is used to make sure of consumers awareness of the products and services that the organization offers. The promotional mix is the combination of the different channels that can be used to transfer the promotional message to the consumers. The channels are represented in advertising, direct marketing, public relations and publicity, personal selling, sponsorship and sales promotion (Rowley, 1998). Thus, sales promotion is one of the most important channels used. Sales promotion is an action that highlights marketing events whose purpose is to have a direct impact on the organization consumer behaviour.

There have been many definitions of sales promotion in literature, but before defining sales promotion, a definition could be given to sales as the interpersonal interaction with prospects and customers so you have to engage in one-on-one meetings, telephone calls and networking. It could be defined as "The activity or business of selling products or services or an alternative term for sales revenue or sales volume." (www.businessdictionary.com)

The sales promotional marketing activities considered to be more efficient than advertising publicity and personal selling (John and William, 1986). Sales promotion includes freebies, contests, discounts, free services, passes, tickets and so on, as distinct from advertising, publicity and public relations. Sales promotion is the effective way of competitive advantage rather than marketing activities (Joncos, 1990). Other researchers think of sales promotion as a direct incentive targeting salesperson, customers or resellers (Gardener and Treved, 1998).

Moreover, researchers have defined sales promotion as an intentional effort from marketers to deliver the appropriate information in suitable inducement way to get the desired acceptable responses from the customers (Zallocco et al, 2008). A very important fact about sales promotions is that it is mostly time-bound programs that demands involvement on the part of the consumer by either immediate purchase or some other action. 
Sales promotion is a direct inducement, proposing special added value for products and services to target salesperson, customers or resellers (William and Ferrell, 1987; Gardener and Treved, 1998). Moreover, sales promotion is considered as an effective method of competitive retaliation rather than marketing activities (Joncos, 1990).

A new definition was provided for sales promotion to be considered as "a range of marketing techniques designed within a strategic marketing framework to add extra value to a product or service over and above the "normal" offering in order to achieve specific sales and marketing objectives. This extra value may be a short-term tactical nature or it may be part of a longer-term franchise-building program" (Brassington and Pettitt, 2000).

Also, sales promotion was defined as a communicating information within two parties, seller and potential buyers, which is obtained to effect customers decisions (Perreault et al, 2006; Shimp, 2003). In addition, sales promotion was defined as an intentional effort from marketers to deliver the appropriate information in suitable inducement way to get the desired acceptable responses from the customers (Zallocco et al, 2009).

The main goals of sales promotion are tactical, strategic, and ultimate. First the tactical goals, they are to tackle a competitor's expanding in market share, to tackle other competitors' promotional efforts, and to move brands that are either declining, overstocked, damaged, or not selling fast enough. Secondly, the strategic goals are to encourage consumers to switch brands, to increase product consumption, to support the marketing efforts for the brand when it comes to communication, and to increase brand loyalty. In the end, the prime goal of a sales promotion is to increase sales, profits, and market share. There are different channels for sales promotions, which include consumer promotions and trade promotions (Shamout, 2016).

\subsection{Sales Promotion Tools}

Sales promotion tools, especially coupons and price reduction are the most extensive used types of promotions (Huff and Alden, 1998; Krishnha and Zhang, 1999).

\subsubsection{Coupons}

Coupons are considered as one of the most important tools used by marketers to motivate consumers. It is the process of submitting vouchers to 
customers to save some money when they want to purchase any type of products later on or in the future. An example of coupons is a $25 \%$ reduction from the main price or a fixed discounted amount like $5 \$$ per piece (Harmon and Hill, 2003; Ndubisi and Chew, 2006).

Coupons have been created to produce product and/or services trial (Robinson and Carmack 1997). Customers can easily be convinced with the coupons method, as it is very useful for trial buying, and it is a good way for brand switching (Cook, 2003). Coupons have many benefits and trends towards the marketers in a way that they can boom the sales in a short period of time and they can stimulate customers to switch to other brands or products (Nudubisi and Tung, 2005). It was referred that consumers are influenced by the price reduction in coupons, which make coupons a smart sales tool (Dark, 2000).

The electronic coupon machines were examined as a good tool to save customers purchasing history. Accordingly, a voucher could be offered depending on customer current bill and on the pervious purchased amount (Kotler and Armstrong, 2006). On the other hand, some researchers showed that coupon is ineffective tool to be used as sales promotion; these studies examined customers behaviour towards great price reduction in coupons, which might result in a negative impact on value of the products and services that the organization may offer, and that can lead to an influence on product trial (Silva-Risso and Bucklin, 2004; Gilbert and Jackaria, 2002).

\subsubsection{Discounts}

Price discount is the process of "reduce the price for a given quantity or increase the quantity available at the same price, thereby enhancing value and create an economic incentive to purchase" (Raghubir and Corfman, 1999). Price reduction is a method where products and services are offered in a good discounted buying price and it seems to be a reduced cost to the consumers. It is frequently used in hypermarkets and point of purchase displays (Fill, 2002). Moreover, price discounts (cut off prices) is playing an important role in stimulating new customers' behaviours to try the offered products (Shimp, 2003). It was found that short-terms peaks in sales get the attention of occasional users of the same brand more likely than getting new customers to purchase the discounted good. Also, it was found that consumers are more to be attracted to price discount promotions (Percy, 2001). It was claimed that product trail has a relationship with price discount, as products trail can be increased by price 
reduction for any product (Ndubisi and Chiew, 2006). Others stated that price reduction has a relationship with different promotion tools in a way that they are affecting each other and pushing the customers to buy the product, such as coupons and samples (Gilbert and Jackaria, 2002). It is also indicated that a great discounted price for any product which happened to be in sales seasons would exercise by dealers because of consumer's price awareness (Smith and Sinha, 2000).

\subsubsection{Buy One Get One Free}

Buy one get one free was defined as one of the common used promotion tools of sales promotion, as the fact that if you buy one product, you get another one for no cost (Sinha \& Smith, 2000). By using this technique, the customer can be easily attracted to buy the product because there is no additional cost and it should be more valued from the customer perspective. Thus, customer can't ignore such great deal. The bonus packages and extra products with no more cost inspire the customer buying behaviour to purchase the product; because customers are getting good feeling towards such offer especially if it is in large sizes packages and properly advertised. Moreover, such promotions increase product trial and customers switching (Gardener and Trivedi, 1998; Percy, Rossiter, and Elliott, 2001). According to Li, Sun \& Wang (2007) Buy one get one free type promotions is a very helpful tool especially to marketers and manufactures who want to clear their stock more quickly.

\subsection{Advertising and Promotions}

Advertising is a mean of communication with the users of a product or service. Advertisements are messages paid for by those who send the messages and are intended to inform or influence people who receive them which may be referred to as the audience (Advertising Association of the UK). Also it may be defined by only one term "salesmanship in print". This means that advertising has almost the same functions of sales which is to describe the characteristics of the product while presenting it efficiently to leave a mark in the customers memory and making them purchase it. Yet the implementation differs since advertising uses mainly seen, heard and touched methods (Chunawella \& Sethia, 2010).

Some people say advertising is simply the way to announce what products are available, who made them, and where you go to buy (Moriarty et al., 2009). In addition to the definition above, (Lane et al., 2011) stated 
that advertising is a message paid for by an identified sponsor and usually delivered through some medium of mass communication. In the communication philosophy perspective, advertising principally is a method of communication that sells goods. So in a broad sense any form of communication that sells something, or delivers sales messages can be identified as advertising. Nowadays, there is different strategic developments, which makes advertising no longer just a method of communication to sell something, but more immense than just selling since it also creates meaning towards something. This step is followed by attaching the brand to become an essential part of people's lives, and then advertising now can be defined as communication that creates perception (Wijaya, 2011). Hence the most recent definition of advertising is any form of communication activities that are directed to create perceptions or certain meanings toward something (product, person, institution, etc).

Advertising and marketing communications were just used to increase sales, but today Advertising is considered one of the important elements of customer service. Development of communications and advertising can create value for customers. The project will create mutually rewarding relationships with customers for the benefit of both the customer and the organization.

Advertising is the core idea that is presented in non-personal ways to create purchase intention. Advertising is done to create likeness, attraction and influence buying behaviour in positive way. Attitude-towards-the ads, is an interesting theory of advertising often used to understand the buying behaviour. Effective advertisement influences the attitude towards brand and finally leads to purchase intention (Goldsmith \& Lafferty, 2002). Advertisers are trying to spread maximum information about products in target market. Therefore, popularity is the aim of advertising (Ramaswami \& Namakumari, 2004).

Similarly, advertising was defined as "a non-personal paid form where ideas, concepts, products or services, and information are promoted through media (visual, verbal, and text) by an identified sponsor to persuade or influence behaviour" (Ayanwala et al., 2005). Advertisers are using different techniques to effectively convey commercial messages to create purchase decision. Hierarchy of effects model often used to assess the effectiveness of advertisement and is a series of steps such as, attention, interest, desire and purchase decision (Cavill \& Bauman, 2004; Grover \& 
Vriens, 2006). Another definition is that advertising is sharing of information about products in a non-personal way usually paid by a sponsor through different media (Datta, 2008).

One of the main points of advertising is to evaluate advertising effectiveness. The Advertising is change in attitude, knowledge and behaviour and informs the audience, encourage, strengthen relations and promote exchanges reminded of the various tasks of advertising. Advertising is an important tool to assess the effects of advertising in each of these cases for Organizations that are essential for sustaining life and development as advertising is a necessity (Brumbaugh, 2002).

One of the main rules for having a successful advertising campaign is to keep your message simple and consistent and repeat it often. In that way, people will remember your message since it is proved that people remember advertising if they see it with great frequency. This explains why you may see the same advertisement two or even three times while watching two hours of television, as this is the way the message will stand out in your mind, yet it is not preferable to overdo it.

Advertising and promotion are usually confused one for the other. Advertising is generally directed to a targeted consumer. The purposes of advertising are many like establishing awareness, providing information, creating brand loyalty, etc...Its strength lies in communicating a positioning or modifying it and sometimes even promotes new uses of a product.

On the other hand, promotion is a general term. It is so general; in fact, that it cannot be named advertising, but sometimes advertising is listed as promotions. However looking for a clear definition or distinction is extremely hard at times as this distinction may be blurry or doesn't exist in some situations. It's better to just recognize that there are many types of promotions.

Using a strategy based on promotions is well-suited for small or medium sized company as it is easy to set up and it provides a short term gain. So, it could be said that the primary difference is in objectives where advertising is aiming to create a long-term brand image while the main objective of promotion is to reach maximum sales quickly. Consequently, the time frame of doing promotion is shorter than that of doing advertising campaigns which is considered the second difference. Regarding the customers, Sales promotion is the direct approach to encourage them to buy a product or services while advertising is an indirect approach that encourages them to buy your products or services. Advertising and 
Promotion also have similarities and these tools of marketing sometimes support each other.

\subsection{Models of Advertising}

To accomplish the best communication, advertisers have defined the consumer's purchase process by using different models. Using theoretical models helps in measuring advertising effects on consumers, setting the goals, structure the objectives, and analyze the impact of the delivered message. In the past century, several models have been proposed for the effectiveness of advertising called the effectiveness of the hierarchical models. The most famous of them was AIDA model that is presented by Elmo Lewis in about 1906. Many models after that had been proposed by theorists, but this model is still considered as coming with a lot of fans (Barry and Howard, 1990).

The name of the AIDA model of advertising is a short form that stands for Attention, Interest, Desire, and Action. It is probably the simplest formula to achieve goals of advertising, yet also it is the most powerful. Therefore, the current study will be based on the AIDA model, which is presented for measuring the effectiveness of advertising. Advertising leads to people from ignorance to knowledge, perception, persuasion, creating enthusiasm purchase (action).

So, AIDA Model describes what happens when a consumer engages with an advertisement. Marketing focuses mainly on grabbing the attention of customers or clients as a way to gain their interest in the product afterwards. Once the company has established the clients' interest in the product, they have to take a step further making the clients desire the product. When they desire the product enough, they are destined to take an action, generally by purchasing the product (Rawal, 2013).

The four stages are introduced in further details as: First stage is drawing attention or creating awareness, which means that before you sell something you need to attract his attention. For the attention of people, there are many ways. As for big title, controversial or shocking content can be ways to attract visits to our promotional message (Barry and Harward, 1990). It is the first thing an ad needs to do to immediately catch the viewer's attention and offer a clear benefit for seeing the rest of the ad. Ads that fail to get the attention of the target customer immediately, means they have lost that viewer for good. The advertiser has to promote the product in such way so the customer becomes aware of the existence of that particular service (Ghirvu, 2013). 
The second stage is to generate interest in the client. This means presenting product features and benefits, people get interested in their product. Music and promoted language should be fit as well with experience and attitudes of customers. In addition to promoting the client's target language, to speak, Layout and content of the customer must also be correct and acceptable (Barry and Harward, 1990). Once the viewers have focused their attention on the ad, the ad needs to make them interested in the product. Consumer interest appears when he actively expresses it in connection to a product or service that he knows about (Ghirvu, 2013). For building the interest, marketers probably use emotions to address the fact that this purchase is a good bargain, the right step, a sound decision, etc. But in addition to that they may also use the logic to convince them. Furthermore letting the customer know what will happen if he/she doesn't buy this product or service proved to beneficial (Rawal, 2013).

Next, the third step comes by creating enthusiasm (to stimulate) in the people. Advertiser must know how to target customers think the advertising message must be able to convince customers that the intention is to introduce and supply of goods, Customer needs will be fulfilled (Barry and Harward, 1990). Interest and desire are two completely different things. An ad needs to convert the viewer's interest into a strong desire for what you're offering. The customer watching the television ad must be strongly motivated and the desire for buying this product must be generated even if need is not there. This can happen only if the ad has used the correct appeal in the advertisement (Rawal, 2013).

The final stage is to end the sale or purchase (buy direct). At this stage of the customer wants in its final decision to purchase and to terminate this process. It is the purchase or sale at this stage of the customer you want to know about buying, and to take its final decision to end the process. The advertiser must be able to give them reassurance that the decision was correct and also people should be able use words to provide advertising content words when talking with others about the product (Bendixen, 1993). After promoting an ad for a brand, the advertisers should ensure that they were able to convince their customers to take an action whether it's a final buy or asking questions to know more about the product. If the ad wasn't attractive and customer hasn't focused on it, there will be no strong positioning in the minds of the customer land your brand will be lost among the lot and lot of brands and advertisements. An ad will be an able to create a strong impact only if it is able to highlight the benefits its target market will get with using the product only then action 
towards a purchase will take place as people will always buy your product when they see the benefits attached with using it (Rawal, 2013). When marketers reach this stage their main focus will be on determining the consumer to finalize the whole cognitive process with a real acquisition and the solid action of buying the product or service (Ghirvu, 2013).

Marketing today is fiercely competitive and products despite having quality need support from promotional team of the organization. AIDA however is an acronym to sales promotion that is necessary to learn in marketing. Using a system like this, allows a general understanding of how to target a market affectively. Moving step by step, AIDA model aims to affectively influence the consumers. It proposes combination of promotional tools that help drawing consumer's interest and generate interest. This process is shown as "AIDA Inverted Triangle". This includes the four stages of: 1 . Attention- where the consumer becomes aware of the product. 2. Interest where an interest in the product develops. 3. Desire - Where the consumer has developed a sense of wanting the product. 4. Action - where a purchase is made (Strong, 1925).

In the case of advergames, they are type of video games that persuade the gamers with something. This means that they "mount procedural rhetoric's effectively". In other words, they create, explain or help in understanding of certain processes, methods, techniques and logics that drive the operation of systems (Bogost, 2007). These particular characteristics of advergames attract and retain the players' attention to focus on a specific brand and make them become aware of it, in a way that traditional media is unable to do (Ghirvu, 2013).

Advergames can produce the interest of the gamer by inserting special advertising that allow the players to interact with the brand and the product. This results in the gamer learning all about special features and characteristics of a product (Ghirvu, 2013).

When it comes to increasing desire video game elements, such as the character design, interface design, or the design of other elements present in the game, play a huge role. Depending on the intentions of the creators, audiovisual, visual and textual layers all helps in transforming interest into desire. Ideally, every layer of the three layers compliment the other, the most important layer being the one that have more relevance in the persuasive structure of the game (Ghirvu, 2013). 
The biggest advantage of advergames is that the online environment put the consumer into an active position, compared to the traditional media which is mostly passive. So video games especially put the player in an active mode and state of mind where he could be easily influenced into getting from desire to action. Marketers can easily use this environment to promote action, as the pleasurable benefit of controlling the game action and experiencing the brand are usually transferred to the user (Ghirvu, 2013).

The figure below explains and summarized what have been previously mentioned regarding AIDA model.

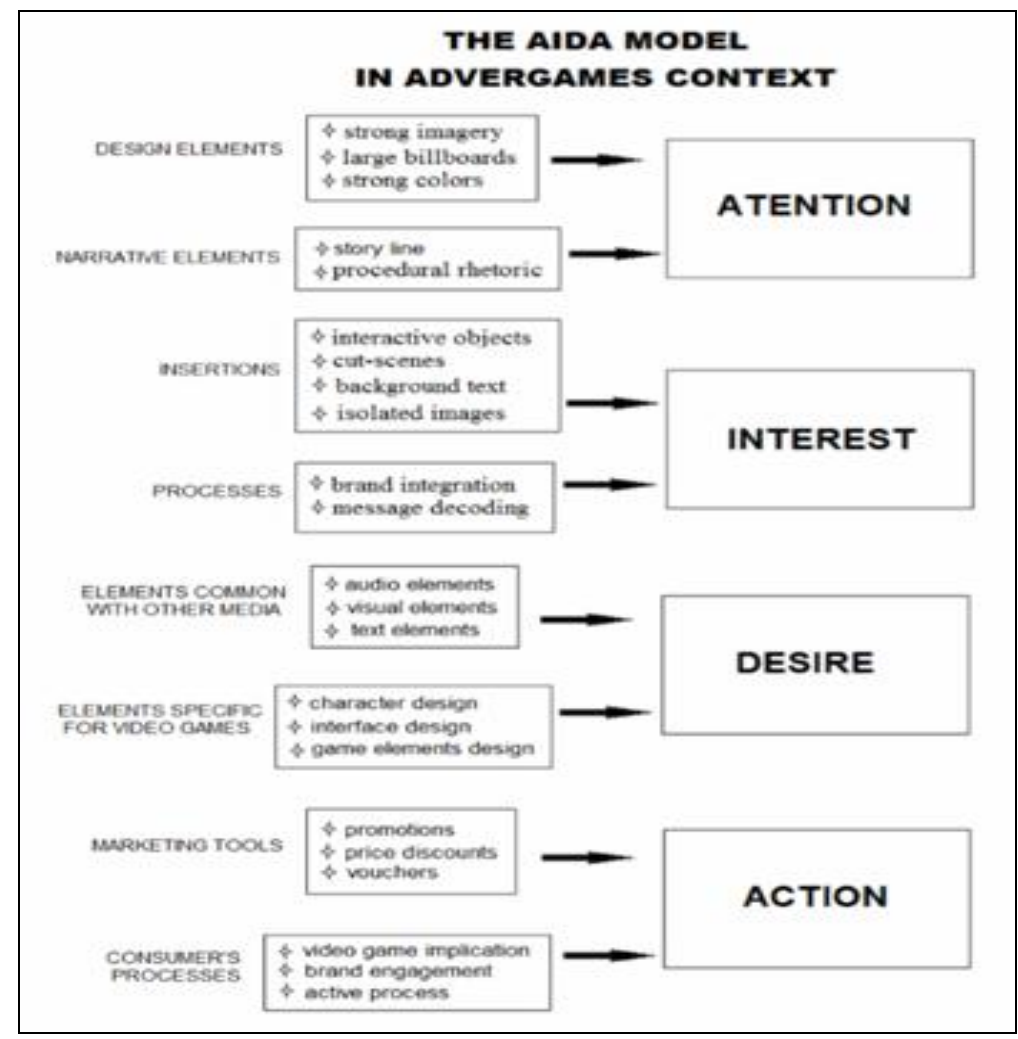

Figure 3.1 AIDA model in Advergames Context

\subsection{Consumer Buying Behaviour}

Consumer behaviour is defined as the activities in which people possess and as well, consume and finally dispose products and services (Blackwell et al., 2001). Ideally, consumers buying behaviour is the 
products purchase decision (Adelaar et al., 2003). It is divided into four views that help in explaining the reasons behind the consumer decision and behaviour. For starters the economic view that has the most impact, followed by the passive view, emotional view and cognitive view. It is also stated that the consumer buying behaviour is based on the method customers decide what product they want, how they evaluate it, and its impact on future purchases (Schiffman and Kanuk, 2004). Like most behaviour and attitudes, consumer behaviour is goal driven too, which means that a choice made after a thorough search may lead the consumer to vast satisfaction as a result of the exerted effort (Kopetz et al 2011). Other social and economic factors may have an effect on the consumers' decisions for example culture and fundamental factors of consumer behaviour (Shamout, 2016).

Consumers buying behaviour has always been given so much importance and space when studying the effectiveness of advertisements and promotions on consumers. The behaviour of the consumers is mostly influenced by their feelings of liking or disliking towards the advertisement of the product. Therefore a successful advertisement or sales promotion is the one that can create an emotional reaction between the product advertised and the receiver of the advertising in a way that influences the consumer behaviour (Fasi, 2016).

There are four classes labelled in consumer behaviour including maintenance which are the necessary choices the consumer take for his physical survival and welfare such as buying food to eat, accumulations which are behaviours involved with the hobby of saving, collecting, and instalment buying, pleasure is affected by the consumption of popular products that produces entertainment, and accomplishment is the behaviour that shows social and economic achievement. (Azad et al, 2013)

The customer behaviour value is affected by four identified independent variables specified as brand awareness, brand Loyalty, perceived quality and brand association (Steel and Torrie, 1960). First in line is the brand awareness, It refers to the customer's ability to remember and recognize the brand leading to the linking of the brand with its competitors product class (Aaker, 1991). The level of brand awareness lies in a relation with brand recognition. A potential consumer cannot buy a product if he's not aware of it since he has to have any kind of awareness of this product so that it can become one of the purchasing choices. This is due to the fact that the product needs to enter the awareness set before it comes 
to the consideration set this could probably the reason why consumers prefer buying a recognizable brand rather than an unfamiliar one (Fouladivanda et al, 2013). There are four types of brand awareness: A) High mental awareness, B) Brand reminding, C) Brand recognition, D) Unawareness (Bumm and Gon Kim, 2005).

Second in line is Perceived Quality which is defined as the customers' perception of the overall quality or superiority of a product or service (Yasin, 2007). A lot of studies concerning the perceived quality have come to the conclusions that product specifications could have little correlation with the perceived quality. The importance of the perceived quality of a brand is that it could help in generating values by providing a vital reason to buy the product. Moreover it helps in the positioning of the brand leading to premium pricing, best performance through motivating channel members, and introducing extensions into new brand categories. In addition, it is found that perceived quality is of utmost importance in determining brand loyalty as well as repeat purchase (Fouladivanda et al, 2013).

Third in line is brand loyalty which an important area of considerable because it constitutes the heart of brand equality. Brand loyalty affects the customer behaviour both positively and negatively since the customer behaviour also has a direct and indirect influence on the brand loyalty. Under the influence of brand loyalty, consumers carry on buying the brand, regardless of the services or prices presented by the competitors (Fouladivanda Et Al, 2013).

Lastly brand association, many researches has stressed on the important role of brand associations. Those researchers confirmed that further equity of a brand is strongly supported by consumers associations towards the brand, which leads to forming a specific brand image (Yasin et al. 2007).Those researchers also argued that brand association is such a complicated concept that connects to one another. Mainly it consists of many ideas, stories, examples, and facts that create a network based on brand knowledge of the tangible products and the intangible qualities. Innovativeness and distinctiveness are the most apparent examples of brand associations (Fouladivanda et al, 2013).

Recently, it has been found that developing the consumers' behaviour leads to one of two things, Brand Loyalty and Brand Switching. Brand loyalty is divided into three steps from a behavioural point of view. The first step is primary behaviour when a customer continues to purchase or use the product. 
The second step is secondary level which is indicated to affect other's behaviours such as word of mouth, and the third step is rebuy intention indicates to consumer future intention to repurchase product or service. Loyalty is an important concept in marketing strategy as the brand loyalty is perceived the center core of brand equity. So based on loyalty customers spend less time searching through the choices. Through over the years the loyalty based purchasing choices might turn into a habit so regular customers turn into loyal customers. Those customers would have benefit for an organization in the reducing costs and implementing its works (Rahmani et al, 2012)

Brand loyalty results eventually in brand equity. Brand equity can be defined as a set of assets and commitments linked to a brand's name and symbol that adds to or subtracts from the value provided by a product or service to a firm or that firm's customers (Aaker, 1996). It is the last result of consumer response to the marketing of that brand based on brand recognition on. Achieving brand equity is having power in a market because of its name, sign and logo is known and preferred (Rahmani et al, 2012).

While brand Switching refers to consumer decision to switch from a brand to another brand different from the one usually purchased. This is due to the previous brand failing to satisfy their needs. According to Lau, Chang, Moon and Liu brand switchers are mostly affected by sales promotions and advertisements which explains sales promotion major role on consumer buying behaviour (Shamout, 2016).

Every decade has its own consumer and today's consumer is a completely different creature than a consumer from three decades ago. Today's consumer has gained many features that simply did not exist past consumers. They are more aware of the countless alternatives and the availability of many product and services that they may need and purchase. Nowadays the level of awareness is increasing in a rate that you cannot possibly compare it with the past consumers. This is due to the globalization and the spread wireless communication (Samli, 2013).

Today's consumers are also well informed about products and brands and about the corporate entities and countries that produce them. They can easily get any information they need by a click of a mouse. They know modern products like Coca-Cola, Nike, and Starbucks, along with hundreds of other products that may be not available in their country, but are available in different parts of the world (Samli, 2013). 
As mentioned earlier, consumers can recognize global products even if they don't exist in their countries. Global brands in the post globalization era can reach consumers easily even in the farthest parts of the world. Because of this recognition the well-known brands are listed so the modern consumer can satisfy his needs by the strong prioritization process (Samli, 2013). Moreover globalization has given the consumer access to products globally which is perhaps the most remarkable chance to get any product produced anywhere, as long as that product is listed in global communication networks. Consumers buy these products from different sources and in different ways (Samli, 2013).

As a result for the mentioned aspects the delivery of products had to develop giving the consumers swift delivery system. It can be understood that the global logistics system have also benefited from globalization which made that consumers expect to receive the product they have ordered from any place in the world in a reasonable amount of time (Samli, 2013).

All of this shows how the consumers nowadays are blessed with vast opportunities that have visible effects on his behaviour while purchasing products. If the consumer a generation ago were capable of ordering a product internationally, they had to wait unknown periods of time to receive them, if at all. Today, the modern consumer is expecting the product to be delivered in a certain period of time.

Culture is a key determinant when it comes to consumer Behaviour since culturally patterned behaviours are perceived as distinct part from economic, political, legal, religious, linguistic, educational, technological and industrial influences (Soares et al, 2007)

The factors that affect the consumers' behaviour phenomenon are many and critical in international circles cultures. Adherents of this latter view it is stated that all the individual's psychological makeup, as well as others who influence the individual, are conditioned by the culture they live in. Culture influencing factors on individuals are both direct and indirect. Direct communication is considered the first factor to affect people. Throughout the human interaction individuals pass through they have already acquired many cultural traits through the adults and children around them (Samli, 2013).

Many studies have been subjected towards the significant impact culture has on consumer behaviour. Some of them state that culture's impact on the individual is limited. Yet others argue that culture is all 
encompassing and a part of it is the consumer behaviour. As individuals are living in different societies with different cultures, they are continuously influenced by interpersonal and personal influences. Due to that they form patterns of behaviour including consumer behaviour based on the cognitive and affective influences. Basically consumers are influenced by for major cultural groups. These are face-to-face groups, people who consumers contact regularly; reference groups, idols and people to which consumers seek to be closely identified as; peer groups, which are composed of the people who are similar to individuals in question; and families, who are likely to have the most profound impact on individuals. There are also cognitive influences, and affective influences, these factors together create what is called culture screens. Those screens not only affect or determine the consumer behaviour but may also manipulate or modify it as needed to maintain the traditional norms. (Samli2013).

Thus there is always an emphasis on maintaining a traditional and accepted norm in a given society when reaching for the consumer through advertisement or promotions. When advertising any product it must be taken into consideration that understanding culture would make it possible to understand and perhaps predict consumer behaviour. Therefore, the basic knowledge of different cultures makes it possible to understand significant differences in consumer behaviours and build on it the plan to contact them (Samli2013).

However, if only one culture or market is being studied solely, then culture can considered as a given in the study. On the other hand, if the research is studying multiple countries, regions, or localities culture becomes a focal point to analyze consumer behaviour patterns that are explained and compared. In this sense, analyzing culture itself may explain and help predict different consumer behaviour patterns.

Consumption behaviour generates certain patterns, to understand the consumer behaviour in different cultures, purchase patterns must be watched closely as they are reflections of consumer behaviour. It is necessary to establish, compare, and analyze the consumption behaviours forming patterns in each society or each market. If the specifics of the purchase patterns are not understood clearly, all the marketing efforts of the marketer would be gone to waste. Two concepts are distinguished when analyzing the purchase pattern: activity orientation and attribute orientation. Activity orientation is orienting individuals seeking help and information to 
comparing alternatives and choices, thus making decisions based on cognitive influences resulting from individuals' efforts. While Attribute orientation opposes activity orientation, Attribute orientation means the consumer was influenced by the attributes of the store, e.g., the merchandise, displays, sales people, and the products he likes (Samli, 2013).

While In collectivistic societies, the consumers' behaviour is greatly affected by the group. Also the main interests are created by the group leader's influence on consumption behaviours, in individualistic cultures, the influences are created from within the individuals' needs and desires. This happens through the efforts of these individuals to seek out these influences and act upon them on their own. Consequently, in these cultures the decisions of consumption are more personalized, private and intrinsic. Marketing efforts are likely to be toward one group or the other, but not to all groups simultaneously. (Samli2013).

The impact of sales promotion on consumer buying behaviour has been widely stated in many researches and studies, they have shown that there are a lot of factors can effect consumer buying behaviour, either to buy or not (Nagar, 2009; Smelser and Baltes, 2001). Sales promotions have a huge impact on consumers buying behaviour such as purchase time, product brand, quantity and brand switching (Nijs et al, 2001). Moreover, consumer purchase decisions sometimes based on the price sensitivity, individuals are more attracted to promoted products (Bridges et al, 2006). There are four views for explaining consumer decision and behaviour such as; economic view, which has the more impact followed by passive view, emotional view and cognitive view (Schiffman and Kanuk, 2004). They also stated that consumer buying behaviour concerned on how customers decide what product they want and how that evaluation is going to be and its impact on future purchases. Some factors affect consumer to buy a specific product such as high purchasing power and other sales physical surroundings (Naimah and Tan, 1999). It was argued that other social and economic factors may affect consumer decisions for example culture and fundamental factors of consumer behaviour (Kotler, 2003).

It is expedient for the marketers to know what happens between the stimuli and consumer's response behaviour (Odugbesan and Gbolahan, 1996). Concerning the marketing mix elements, the behaviour of market has to be well comprehended in order to structure the market mix element in an optimal manner for better positioning within selected marketing segments. 
The consumers' characteristics and their influences serve as a major ingredient in the buyer's perception about stimuli and their purchase decision making process, hence, it was stated that the marketing manager needs to view the consumer as a problem solver due to the fact that consumer is a decision making unit that takes in information, processes it in light of existing situation, take actions to accomplish satisfaction that enhances lifestyle (Hawkins et.al, 1989). It is obvious that consumer behaviour is the soul of marketing concept. One should not lose sight of certain factors which influence consumer behaviour such as cultural, social, personal, psychological and situational factors are all comprehensive approach to buying behaviour acknowledgement that makes man a complex creature. Interestingly, some researchers have also shown that sales promotion is likely to repeat purchases if consumers are satisfied with the brand that is being promoted; it is more likely that they will also buy it later after the promotion is over (Peattie and Peattie, 2009).

However, it was concluded that sales promotions should be handled with care the outcomes vary from products or services to consumer groups is the situational factors play a major role in the outcome analysis bearing in mind that most promotions research are based on the context of USA markets hence the implications differ if applied to Nigerian markets. The problem facing sales promotions on consumer purchases behaviour in Nigeria are that, whether consumers' purchase behaviour towards sales promotional efforts yield positive or negative for the product concerned since manufacturing organisations operate under inflexible competitions and increasing harsh challenges that make it almost impossible for the organisation to meet the profitability target and reasonable return on investment of shareholder funds. Most organisations now concentrate their efforts on promotion strategies and techniques to reach the dwindling profit problem.

Promotion being a short-term incentive is to encourage purchases (Kotler, 2008) and is combined with advertising. It is not all sales promotion techniques that are directed to consumers, some are directed to the middle men and some to the organisation's own sales force (Govon, 2006). One gets involved in making decisions of the product to buy which is now a problem solving process that is dependent on the consumer's level of involvement which is the degree of interest on a product or service. The high involvement products are those that are not expensive with less society risk attached to them (Witton, 2006) Choosing between 2 brands put one in 
a position to make decisions but if there is no alternative, one is literally forced to buy because there is no choice to choose from and this does not constitute a decision, such a no-choice decision is commonly referred to s a "Hobson's Choice" (Achumba, 2000). Due to its present economic recession in the world at large, this brought about increased economic pressure on the consumer and a corresponding increase pressure on the consumers' disposal income which lead to consumers becoming more conscious and rational in their purchasing decisions (Buel, 2004). Promotion becomes increasingly important in marketing as it serves as a way of increasing the demand for products, as a substitute for price competition and as a way of differentiating similar products (Osuagwu and Eniola, 1998).

\subsection{The relationship between sales promotions and consumer buying behaviour}

According to Quelch (1989) promotional tools, materials and techniques have dramatically increased in the recent years by marketers. Then, it was admitted that sales promotion has an impact on consumer buying behaviour by focusing on promoting occasion (Blattberg and Neslin, 1990). It was argued that customer's promotion acceptance is based on the out and in store sales promotion (Schneider and Currim, 1991). Later on, it was indicated that sales promotion has a direct effect on customers' behaviours.Chandon (Schultz, 1998), it was pointed that there are other factors can influence consumer buying behaviour rather than reasons beyond price saving (Wansink and Laurent, 2000). It was argued about sampling which is a good technique and it has less cost and an effective tool to attract customers (Pramataris, 2001). It was indicated that promotion tools has a huge impact on consumer buying behaviour during any competition; therefore discounted price one of these tools which effect customers decisions (Fill, 2002). In addition, sales promotion can result in increasing sales volume with less profit (Pickton and Broderick research, 2005). Others also agreed that sales promotions' is aiming to influence consumer buying behaviour by introducing new brand product which is going to be targeted the customers who have no previous experience with it(Solomon, Marshall and Stuart, 2008; Kotler and Armstrong, 2004). However, it was found that psychological variables have a significant relationship with sales promotion; therefore they concluded that there is no significant relationship between impulsive behaviour and sales promotion (Esfahani and Jafarzadeh, 2012). 
When measuring behavioural Responses to Sales Promotion on Muslim consumers in Egypt a study was made to compare the three most common promotional tools in Egypt - price discounts, bonus packs and product display/sampling -and understand how they influence consumers' behavioural responses. The study concentrated on three hypotheses, the first one is that there is a positive significant relationship between price discounts and consumer behavioural responses. The second hypothesis is there is a positive significant relationship between bonus packs and consumer behaviour responses and the last one is there is a positive significant relationship between product display/sampling and consumer behavioural responses (Farrag, 2010). A number of 410 questionnaires were distributed yet only 318 were admitted with credible information. The respondents were chosen to be shoppers who visit hypermarkets on a regular basis. To test the relationship between the different promotional tools and behavioural responses Pearson Correlation was used (Farrag, 2010).

The first finding related to the relationship between price discounts and consumers' behavioural it was clear that there is an overall positive correlation. Based on this finding price discounts are related to approximately 54\% variation in consumer's overall behavioural responses. This means that Egyptian consumers are sensitive to prices as that's why price discounts plays the most significant role in shaping consumers' brand switching behaviour (45\%) and spending more $(61 \%)$ in super and hyper markets compared to other promotional tools (Farrag, 2010)

When it comes to product displays and sampling, it is proven that it also has a significant role but in shaping only the following types of behaviours; stockpiling (45\%) product trial (40\%,) followed by spending more (36\%) (Farrag, 2010). Finally, the findings of the bonus packs' research has only supported two types of behaviours: purchase acceleration (39\%) and stockpiling (44\%).These findings are related immensely to the economic conditions prevailing in Egypt and most Islamic nations. As those cultures tempt individuals to stockpile and purchase more quantities earlier than planned to save money and benefit from the price or quantity discount (Farrag, 2010).

Sales promotion is the perfect method to increase sales volume. It is also agreed that sales promotions' can influence consumer buying behaviour by in many ways for instance, introducing new brand product which is going to be targeted the customers who have no previous experience with it. However, it was found that psychological variables can impact sales promotion 
significantly; therefore it was proved that sales promotion has no significant impact on impulsive buying behaviour (Esfahani and Jafarzadeh, 2012).

A model for evaluating the effects of marketing mix's efforts and also for company image on brand equity in the software section of information technology was presented by Kim and Hyun at 2010. The model's results have shown that all the efforts of marketing mix affected the overall value of the brand which happens by increasing customers' buying activities (Rahmani Et Al, 2012). Costumers are deeply affected by advertisement as they tend to believe their claims and assume that they are truly presenting the probable functions of the product. Therefore, when the advertisement is aired frequently the costumers not only gain awareness and mental association, but also they gain more positive perception resulted in powerful buying actions. One of the major aspects in the increasing or the decreasing of customer loyalty is the frequency of ads. This means that advertising helps in empowering the brand loyalty (Rahmani Et Al, 2012).

Through experimental presenting of the actual product, brand equity has a powerful and unique connection with promoting events that aims for long-term (koler, 2008). Since the audience's reaction is more visible and stronger to sale promotions, they excel when used for better representing and sale increase in stagnation. Still marketers should put in mind that a tool is short term and in order to make the best of them managers should apply it in intervals with long- term goals (Rahmani Et Al, 2012).

A study based on 200 questionnaires was made to get better understanding and more reliable data in regards to the consumer behaviour towards sales promotion, in this research it was agreed that price discount has a strong positive correlation with consumer buying behaviour (Mughal Et Al, 2014).

Another research was implemented to analyze the relationship between sample and consumer behaviour through a field study, which applied an actual free-sample program implemented by a US grocery store chain. It was noticed that the purchase rate for the promoted product was significantly higher for samplers (40 percent) versus non-samplers (seven percent). Therefore, a very effective tool to encourage consumers to switch from planned to promoted brand is free sampling tool. It is also a very effective method to stimulate individual behaviour towards purchasing decisions. So, retailers should focus more on sampling to increase the sales of the promoted product (Mughal Et Al, 2014). In this research, around 200 
respondents were asked to participate in self-administrative survey in order to analyze the link between the buy one get one promotions and consumer behaviour. The data has proved that buy one get one free has a positive relationship with buying behaviour, but the significance value was less than 0.05 (Mughal Et Al, 2014). To study the relation between coupon and consumer behaviour a questionnaire was used for this study besides a face to face interviews with respondents. The there is no significant differences across the different buying behaviours depending on coupons. Accordingly, coupon has no significant influence on reported purchase activity. (Mughal Et Al, 2014)

\section{Research Framework}

\subsection{Research Design}

An online survey is developed and distributed randomly to 800 respondents through a face-to-face questionnaire with customers of retails stores in Egypt. The population under study is all customers of retail stores in Egypt, where a number of 800 customers are selected as a random sample to test the hypotheses under study. The number of respondents was selected so as to be adequate to a $99 \%$ confidence interval. The questionnaire contains two main sections. The first part contains the background of a person who answers the questionnaire, while the second part shows the consciousness with respects to a variety of promotion tools, advertising techniques and purchasing behavior of persons who answer the questionnaire. In the first portion, every person who answer the questionnaire were told to provide the information about age, gender, education, monthly income, and his or her status. In the second portion of survey questionnaire, each variable was measured using five items except the purchaser buying behaviour, where eight items were used in its measurement. In this study, likert scales of five point were used, 1 for (strongly disagree), and 5 for (strongly agree). This scale is adopted from the Bakewell and Mitchell (2003), David Yoon Kin tong, Kim Piew Lai, Xue La Tong (2012) study. To analyze the data, the Statistical Package for Social Science (SPSS) version 22.0 was used.

\subsection{Research Hypotheses}

The survey was directed to figure out responses for the following hypotheses developed from the proposed research model: 
$\mathbf{H}_{\mathbf{1}}$ : There is a significant relationship between different Promotion tools provided and Consumer Behavior.

H1a: There is a significant relationship between coupons and consumer buying behaviour.

H1b: There is a significant relationship between price discount and consumer buying behaviour.

H1c: There is a significant relationship between buy one get one free and consumer buying behaviour.

$\mathbf{H}_{2}$ : There is a significant relationship between AIDA model advertising techniques and Consumer Behaviour.

H2a: There is a significant relationship between Attention and consumer buying behaviour.

$\boldsymbol{H} \mathbf{2 b}$ : There is a significant relationship between Interest and consumer buying behaviour.

H2c: There is a significant relationship between Desire and consumer buying behaviour.

H2d: There is a significant relationship between Action and consumer buying behaviour.

Also, the research under study includes the following questions:

Q1: What are the sales promotion activities affecting the consumer buying behaviour?

Q2: What is the most important activity of sales promotion affecting consumer buying behaviour?

Q3: What are the Advertising promotion activities affecting the consumer buying behaviour?

Q4: What is the most important activity of Advertising promotion affecting consumer buying behaviour?

\subsection{Research Framework}

Accordingly, the research framework could be represented using the following figure: 


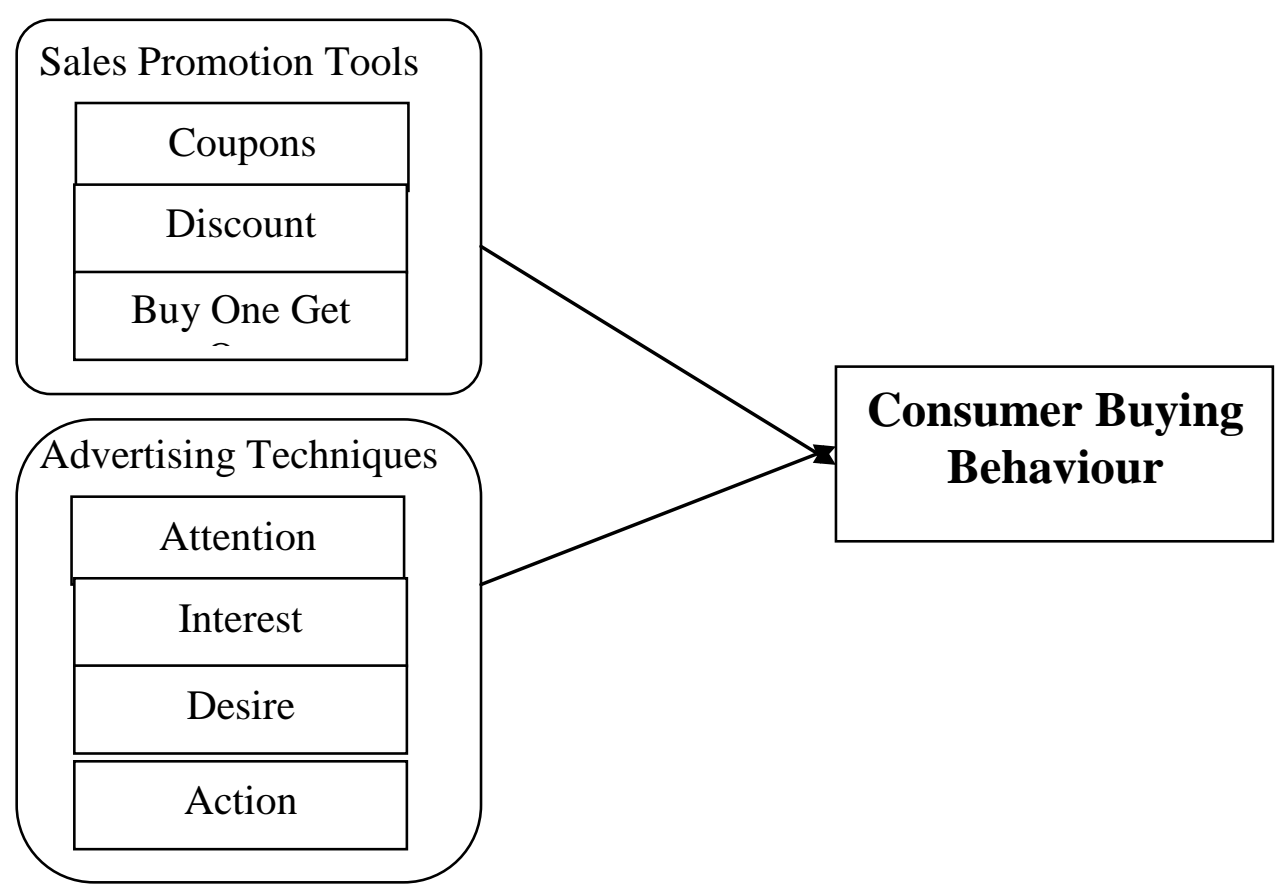

Figure 5.1 Research Framework

As observed from the figure above, the independent variables include Sales promotion tools; Coupons, Price Discounts and Buy One Get One Free, as well as the advertising techniques of AIDA model; Attention, Interest, Desire, Action. The dependent variable is considered as the consumer buying behaviour.

\section{Results and Discussion}

The data under study is analyzed in this section using the SPSS program - version 22 and AMOS - version 18. Data was tested for its validity and reliability before being used in the analysis. After that, the hypotheses under study are tested using the correlation and regression analysis, as constructing the Structural Equation modelling (SEM).

\subsection{Descriptive Analysis}

The frequency and percentages of the variables and demographics under study are presented in the following table. It could be observed that the greatest percentage of sample under study lies in the area of agreement. 
This reflects that most of the sample under study observed the importance of the promotion tools used, as well as the importance of enhancing those tools with the dimensions of Attention, Interest, Desire, Action.

Table 6.1 Descriptive Analysis of the variables under study

\begin{tabular}{cccccc}
\hline \multirow{2}{*}{ Variable } & \multicolumn{5}{c}{ Frequency } \\
\cline { 2 - 6 } & $\begin{array}{c}\text { Strongly } \\
\text { Disagree }\end{array}$ & Disagree & Neutral & Agree & $\begin{array}{c}\text { Strongly } \\
\text { Agree }\end{array}$ \\
\hline Coupons & 10 & 13 & 187 & 391 & 199 \\
Discounts & 23 & 75 & 102 & 390 & 210 \\
Buy One & 7 & 24 & 191 & 442 & 136 \\
Attention & 16 & 29 & 57 & 421 & 277 \\
Interest & 11 & 14 & 129 & 226 & 419 \\
Desire & 14 & 18 & 181 & 388 & 382 \\
Action & 10 & 22 & 192 & 402 & 365 \\
Consumer Behaviour & 10 & 27 & 133 & 386 & 434 \\
\hline
\end{tabular}

\subsection{Data Testing using Reliability and Validity}

Reliability analysis evaluates the properties of measurement scales and the items that make them up (Coakes and Steel, 2007). To verify the reliability of the research constructs, the internal consistency analysis (Cronbach's alpha) and item-to-total correlation are used to identify the internal consistency reliability of the proposed constructs. Cronbach's alpha is suggested to be above 0.70. This study has overall construct Cronbach's alpha $(\alpha)=0.798$ where it is considered as acceptable level for reliability. Also, the reliability of the research variables are shown in table 6.2, observing adequate reliability.

Validity tests the data using factor analysis (multivariate technique) that confirms whether or not the theorized dimensions are applicable (Sekaran \& Bougie, 2005). Convergent validity was essential to ensure that the items measuring the same construct are highly correlated (Hair et al., 1998). The average variance extracted (AVE) represents the average community for each latent factor. It should be greater than 0.5 , which means that the factors should explain at least half the variance of their respective 
indicators (Hair et al., 1998). Table 5.2 shows the AVE of the research variables, showing adequate validity.

Table 6.2 Validity and Reliability of the variables under study

\begin{tabular}{l|c|c}
\hline \multicolumn{1}{c|}{ Variables } & AVE & Cronbach's Alpha \\
\hline Coupons & 65.782 & 0.771 \\
Discounts & 79.571 & 0.819 \\
Buy One & 83.427 & 0.735 \\
Attention & 63.980 & 0.842 \\
Interest & 59.099 & 0.866 \\
Desire & 85.917 & 0.821 \\
Action & 78.234 & 0.788 \\
Consumer Behavior & 56.212 & 0.702 \\
\hline
\end{tabular}

\subsection{Hypotheses Testing}

In this section, each hypothesis is tested separately using the assigned tools of analysis.

\subsubsection{Testing the First Hypothesis}

To test the first hypothesis, the regression analysis and the structural equation modelling were used. Table 6.3 shows the results of the regression analysis, which assesses the direct relationship between variables as well as showing the causal relationship and the nature of relationship between variables (Aiken et al., 1991; Foster et al., 2001).

It was found that there is a significant impact of all sales promotion tools; Coupons, Price Discounts, and Buy One Get One Free on Consumer Behaviour, as p-values are less than 0.01. Also, it could be claimed that Buy One Get One Free have the highest impact on consumer behaviour as the corresponding standardized coefficient is equal to 0.254 , which is the highest coefficient compared to that of Price Discounts (0.134) and Coupons (0.126). 
Table 6.3 Regression Analysis for impact of Sales Promotion Tools on Consumer Behaviour

\begin{tabular}{|c|c|c|c|c|c|c|}
\hline & \multirow[t]{2}{*}{ Model } & \multicolumn{2}{|c|}{$\begin{array}{l}\text { Unstandardized } \\
\text { Coefficients }\end{array}$} & \multirow{2}{*}{$\begin{array}{c}\begin{array}{c}\text { Standardize } \\
\text { d }\end{array} \\
\text { Coefficients }\end{array}$} & \multirow[t]{2}{*}{$\mathbf{T}$} & \multirow[t]{2}{*}{ P-value } \\
\hline & & B & Std. Error & & & \\
\hline \multirow{4}{*}{1} & (Constant) & 10.212 & .071 & & $\begin{array}{c}16.49 \\
7\end{array}$ & .000 \\
\hline & Coupons & .135 & .032 & .126 & 3.469 & .000 \\
\hline & Price Discounts & .165 & .016 & .134 & 3.971 & .000 \\
\hline & $\begin{array}{l}\text { Buy One Get One } \\
\text { free }\end{array}$ & .276 & .014 & .254 & 4.198 & .000 \\
\hline
\end{tabular}

\subsubsection{Testing the Second Hypothesis}

To test the current hypothesis, the regression analysis is used. Table 6.4 shows the regression analysis of the direct impact of the research variables; Attention, Interest, Desire and Action on Consumer Behaviour. It could be observed that there is a significant positive impact of Attention on Consumer Behaviour $(\beta=0.067, \mathrm{P}$-value $=0.017<0.05)$. Also, it was observed that there is a significant positive impact of Desire and Action on Consumer Behaviour $(\beta=0.044$ and 0.133 , P-value $=0.003$ and 0.000 respectively). On the other hand, it could be observed that Interest shows an insignificant impact on Online shopping Behaviour in the presence of other factors $(\mathrm{P}$-value $=0.554>0.05)$.

Observing the standardized coefficients, it could be observed that Action shows the most significant impact on Consumer Behaviour, as it has the largest standardized coefficient relative to other research variables (Standardized $\beta=0.278$ ). Also, Attention comes in the second rank (Standardized $\beta=0.144$ ), while Desire shows the least significant impact on Consumer Behaviour (Standardized $\beta=0.137$ ). 
Table 6.4 Regression Analysis of the impact of Research Variables on Consumer Behavior

\begin{tabular}{ccccccc}
\hline \multirow{2}{*}{ Model } & \multicolumn{2}{c}{$\begin{array}{c}\text { Unstandardized } \\
\text { Coefficients }\end{array}$} & $\begin{array}{c}\text { Standardized } \\
\text { Coefficients }\end{array}$ & T & $\begin{array}{c}\text { P- } \\
\text { value }\end{array}$ \\
\cline { 2 - 5 } & $\mathbf{B}$ & Std. Error & Beta & & \\
\hline & (Constant) & 1.413 & .086 & & 16.497 & .000 \\
& Attention & .067 & .028 & .144 & 2.393 & .017 \\
1 & Interest & .013 & .022 & .026 & .592 & .554 \\
& Desire & .044 & .015 & .137 & 3.010 & .003 \\
& Action & .133 & .029 & .278 & 4.534 & .000 \\
\hline
\end{tabular}

$\mathrm{R}^{2}=70.3 \%$, F-test $=49.463, \mathrm{P}$-value $=0.000$

\subsubsection{Testing the impact of Sales Promotions and Advertising Techniques on Consumer Behaviour using SEM}

Amos 18 program is used to test hypothesis of the current research based on the maximum likelihood for the research variables. Table 5.5 displays the model fit indicators of CFA, which are the minimum discrepancy (CMIN), goodness of fit index (GFI), comparative fit index (CFI), incremental fit index (IFI), Tucker-Lewis index (TLI), and root mean square of approximation (RMSEA).

As mentioned by Hoelter, (1983), that the minimum discrepancy (CMIN) provides an indicator as to whether or not the estimated and observed matrices are different from each other. The GFI is a measure of the relative amount of variance and covariance in the sample covariance matrix that is jointly explained by the population matrix. The CFI provides an estimation of the fit of the hypothesized model being tested against that of a baseline model. Another index; which compares the hypothesized model with a baseline model, is the TLI, GFI, CFI or TLI index. If their values are close to one, then they indicate a good fit. There values could be within a range from zero to one. The RMSEA is one of the most informative criteria in covariance structure modeling, because it measures the amount of error present when attempting to estimate the population. 
In the current research, SEM is employed in testing the hypothesis of the study beside the overall model that represents the summation of scale indicators. It was found that the values of the above mentioned indicators are almost acceptable.

\section{Table 6.5 Fit measures of the Structural Equation Modeling}

\section{Source: AMOS}

\begin{tabular}{ccc}
\hline Measure & $\begin{array}{c}\text { Model } \\
\text { Results }\end{array}$ & Threshold \\
\hline $\begin{array}{c}\text { Chi-square/df } \\
\text { (cmin/df) } \\
\text { p-value for the } \\
\text { model }\end{array}$ & 1.627 & < 3 good; < 5 sometimes permissible \\
NFI & 0.000 & $<\mathbf{0 . 0 5}$ \\
TLI & 0.544 & $>\mathbf{0 . 9 0}$ \\
IFI & 0.691 & $>\mathbf{0 . 9 5}$ \\
CFI & 0.756 & $>\mathbf{0 . 9 5}$ \\
RMSEA & 0.738 & $\mathbf{0 . 9 5}$ great; $>\mathbf{0 . 9 0}$ traditional; $>\mathbf{0 . 8 0}$ \\
sometimes permissible
\end{tabular}

Table 6.6 shows that there is a significant impact of all sales promotion tools on consumer behaviours, as all corresponding p-values are less than 0.01. Regarding advertising techniques, it was found that there is a significant impact of Attention, Desire and Action on Consumer Behavior (P-value < 0.05), while, it was found that there is an insignificant impact of Interest on Consumer Behavior (P-value > 0.05).

In general, it could be claimed that the results obtained from Regression and SEM are almost the same.

Also, it was found that different sales promotion activities have a significant impact on changing the customer behaviour towards buying certain products or services. Also, buying one get one free, as one of the sales promotion methods, shows the highest impact on consumer behaviour while coupons shows the least impact on consumer behaviour. 


\section{Table 6.6 Model Estimates of the Structural Equation Modelling}

Source: AMOS

\begin{tabular}{lccccccc}
\hline & & & Estimate & S.E. & C.R. & P \\
\hline Consumer Behaviour & $<---$ & Attention & .163 & .040 & 4.091 & $* * *$ \\
Consumer Behaviour & $<---$ & Interest & .070 & .040 & 1.781 & .075 \\
Consumer Behaviour & $<---$ & Desire & .107 & .036 & 2.972 & .003 \\
Consumer Behaviour & $<---$ & Action & .240 & .047 & 5.152 & $* * *$ \\
\hline Consumer Behaviour & $<---$ & Coupons & .243 & .035 & 5.152 & $* * *$ \\
Consumer Behaviour & $<---$ & Discount & .287 & .021 & 4.724 & $* * *$ \\
Consumer Behaviour & $<---$ & Buy One Get One & .321 & .028 & 6.212 & $* * *$ \\
\hline
\end{tabular}

Accordingly the first hypothesis is accepted, where:

$\mathbf{H}_{1}$ : There is a significant relationship between different Promotion tools provided and consumer behaviour.

Regarding the second hypothesis, it was found that there is a significant positive impact of Attention on Consumer Behaviour, which supports the First hypothesis under study and by that the researcher accepts the hypothesis that:

$\mathbf{H}_{2 \mathbf{a}}$ : There is a significant relationship between Attention and Consumer Behaviour.

It could be observed that there is a significant positive impact on Desire on Consumer Behaviour, which supports the third hypothesis of the study and by that the researcher accepts the hypothesis that:

$\mathbf{H}_{2 \mathbf{c}}$ : There is a significant relationship between Desire and Consumer Behaviour.

In addition, it was observed that there is a significant positive impact of Action on Consumer Behaviour, which supports the fourth hypothesis under study and by that the researcher accepts the hypothesis that:

$\mathbf{H}_{\mathbf{2 d}}$ : There is a significant relationship between Action and Consumer Behavior. 


\section{Conclusion and Recommendations}

Overall, sales promotion tools are playing an important role to stimulate customers towards buying any promoted product, and that will definitely increase dealers and retailers profit and market share. In this study, it was shown that consumers behaviour can be positively induced by using various promotion tools such as; coupons, price discount, and buy one get one free. Also, it was found that promotion tools such as coupon have not that high influence on consumer buying behaviours like Buy One Get One Free. Thus, the retail sector has to focus on the tool of Buy One Get One Free as well as using other tools to give varieties of promotions.

Regarding advertising techniques, it could be claimed that companies in retail sector in Egypt have to focus on Attention, Desire and Action, while they may ignore interest as one of the advertising tools.

Any research focuses on one aspect of a certain issue to provide a better description and explanation. Similarly, this research has focused on the effect s sales promotion on consumer interest to purchase. The following suggestions are proposed for further research:

1. Investigating the effect sales promotion using other models rather than AIDA model.

2. Investigating the consumers' attitude towards sales promotions in other countries.

3. Investigating about other Marketing Mix instruments using the present model.

\section{References}

Aaker, D. A. (1996).Measuring brand equity across products and markets. California Management Review, 38 (1), 100-120. Banks, J., \& Moorthy, S. (1999) “A model of price promotion”. International Journal of Industrial Organization, Vol. 17, pp. 371-398.

Bawa, K. \& Shoemaker, R.W. (1987).The effects of a direct mail coupon on brand choice behavior.Journal of Marketing Research. 24, 370-376 Belch EA, Belch EL. (1996), The effects of reference prices in retail advertisements. Journal of Marketing; 45(2):61-69.

Belch EA, Belch EL. (1996), The effects of reference prices in retail advertisements. Journal of Marketing; 45(2):61-69. Blackwell, R.D., 
Miniard, P.W. and Engel, J.F. (2001), “Consumer Behavior”, 9th ed. Fort Worth, TX: Harcourt College Publishers.

Blattberg RC, Neslin, S.A. (1990).Sales Promotion, Concepts, Methods and Strategies.New Jersey, Englewood Cliffs.Prentice Hall.

Brandweek. (1994), Promotional influence spurs buyers to try something new. Brandweek. 35 (12): 32-34. Brassington F, Pettitt S. (2000). Sales Promotion In: Principles of Marketing. 2nd ed, FT Prentice Hall, Harlow. pp. 642-685.

Brassington, F. \& Pettitt, S. (2006) Principles of Marketing. 4th ed. Prentice Hall

Bridges, E., Briesch. R. A. \& Yim, C. K. (2006), Effects of prior brand usage and promotion on consumer promotion response. Journal of Retailing, 82 (4), 295-307

Brumbaugh, A. M. (2002), "Source and nonsource cues in advertising and their effects on the activtion of cultural and subcultural knowledge on the route to persuasion", Journal of Consumer Research, Vol. 29 No. 2, pp. 258-69.

Cadogan, T. W. \& Foster, B. D. (2000). Relationship selling and customer loyalty: an empirical investigation. Marketing Intelligence and Planning, 18 (4), 185-199.

Chandon, P., Laurent, G. and Wan sink, B. (2000) "A benefit congruency framework of sales promotion effectiveness" Journal of Marketing. Vol. 64, No. 4, pp. $65-81$

Chen, J. \& Ching, R. K. H. (2007). The effects of mobile customer relationship management on customer loyalty: brand image does matter. In Proceedings of the 40th Hawaii International Conference on System Sciences, 1-10.

Chen, Y., Chen, C. \& Hsieh, T. (2007).Correlation of service quality, customer satisfaction customer loyalty and life style at hot springs hotels. Journal of International Management Studies, August, 51-59.

Chunawala S.A., Sethia K.C. (2010), Foundations of Advertising Theory \& Practice, Himalaya Publishing House, Mumbai, seventh Edition

Cook, A. (2003), How to cash in on the coupon craze. Incentive Business. Jun/Jul: 3 Cotton, B. C, and Emerson M. Babb. (1978), "Consumer Response to Promotional Deals", Journal of Marketing, 42(3), pp. 109113. 
Crain Books, Chicago Shimp, T.A. (2003) "Advertising Promotion and Supplemental Aspects of Integrated Marketing Communications" 6th ed., USA: Thomson South-Western.

Darks, M.C. (2000).Calling all Coupon Clippers.Business News New Jersey. 13(13): 16.

DelVecchio, D. Henard, D. H. \&Freling, T. H. (2006). The effect of sales promotion on post promotion brand preference: a meta-analysis. Journal of Retailing, 83 (3), 203-213.

Dick, Alan S. and KunalBasu. (1994), "Customer Loyalty: Toward an Integrated Conceptual Framework," Journal of the Academy of Marketing Science, 22 (2), 99-113.

Ehrenberg, A.S.C., Hammond, K. \&Goodhardt, G.J. (1994), The aftereffects of price related consumer promotions. Journal of Advertising Research. 34 (4): 11-21.

Esfahani AN, Jafarzadeh M. (2012).Studying impacts of sales promotion on consumer's psychographic variables: A Case study of Iranian chain stores at City of Kerman. Interdisciplinary Journal of Contemporary Research in Business; 3(9):12781288.

Evan, M., Moutinho, L. \& Ranji, W. F. V. (1996).Applied consumer behavior. Addison-Wesely Publication Co.:

Gardener E,Trivedi M. (1998), A communication framework to evaluate sale promotion strategies. J. Advert. Res., 38 (3): 67-71.

Garvin, G. A. (1988). Managing quality: the strategic and competitive edge. New York: Free Press

Gilbert, D.C. and Jackaria, N. (2002), "The efficacy of sales promotions in UK super markets: a consumer view", International Journal of Retail \& Distribution Management, Vol. 30No. 6, pp. 315-22.Journal of Product \& Brand Management, Vol. 13 No. 5, pp. 303

Harlow Readind. Evan, M., Moutinho, L. \& Ranji, W. F. V. (1996).Applied consumer behavior. Addison-Wesely Publication Co.:

Harlow Readind. Fill, C. (2002) Marketing communications: Contexts, strategies and applications, 3rd ed. Italy: Pearson Education Limited

Susan K. Harmon, C. Jeanne Hill. (2003), "Gender and coupon use ", Journal of Product \& Brand Management, Vol. 12 Iss: 3, pp.166 - 179 
Huff, L.C. \& Alden, D.L. (1998). An Investigation of Consumer Response to Sales Promotions in Developing Markets: A Three Country Analysis. Journal of Advertising Research. 38 (3), 47-56.

John F. Luick and William, L. Zieger. (1986), Sales promotion and Modern Merchandising, New York: MC Graw Hill 11.

Joncos L. (1990), A retailer promotion policy model considering promotion signal sensitivity. Marketing Science; 12(4):339-356. Jones, T. O. Sasser, W. E. (1995). Why satisfied customer defect. Harvard Business Review, 73 (6), 88-99.

Jorge M. Silva-Risso, Randolph E. Bucklin. (2004), Capturing the Effect of Coupon Promotions in Scanner Panel Choice Models" , Journal of Product and Brand Management, Vol.13 (6), pp.442-452

Kardes, F. R. (1999), "Consumer Behaviour: Managerial Decision Making" New York: Addison Wesley Longman. Kenneth E. Clow, Donald Baack. (2007), Integrated advertising, promotion, and marketing communications, page: 509-510

Katke, K. (2007). The Impact of Television Advertising on Child Health \& Family Spending. International Marketing Conference on Marketing \& Society. Retrieved on Dated: 10-04-2009 from http://www.itu.int/ITUD/ict/newslog/content/binary/20-2008jpg.

Kopalle, P. K., \& Mela, C. F. (1999) "The dynamic effect of discounting of sales: Empirical analysis and normative pricing implications" Marketing Science, Vol. 18, No. 3, pp. 317-332.

Kotler P. (2003), Marketing Management. Delhi: Pearson Education. Kumar SR (2007). Marketing and Branding, The Indian Scenario.

Kotler P. \& Armstrong G. 2006. Principles of marketing, (11th Ed.) Upper Saddle River: New Jersey: Prentice-Hall.

Krishna, A., \& Zhang, Z. J. (1999). Short or long duration coupons: The effect of the expiration date on the profitability of coupon promotions. Marketing Science, 45(8), 1041-1057

Mercer, Vilela, Ganzalezthe, Johnston \& Marshall.(2002) Role of Selling in Marketing Strategy.

Ndubisi O.N. (2005), Customers Behavioral Reponses to sales promotion: The Role of Fear of Losing Face, Vol. 17, No.1, pp.32-49 
Ndubisi, N. O., and Chew, T. M. (2006).Awareness and Usage of Promotional Tools by Malaysian Consumers: The Case of Low Involvement Products. Management Research News.

Perreault, S., Gaudreau, P., Lapointe, M.-C., \& Lacroix, C. (2007). Does it take three to tango? Psychological need satisfaction and athlete burnout. International Journal of Sport Psychology, 38, 437-450.

Raghubir, P. and K. Corfman (1999), "When Do Price Promotions Affect Pretrial Brand Evaluations?," Journal of Marketing Research, 36 (May), 211-22.

Rowely, J. (1998), Promotion and marketing communications in the information, Library Review, Vol. 47 No. 8, pp. 383-387

Robinson, W.A., \& Carmack, L.L. (1997), Best Sales Promotions, (6th Volume). New York: NTC Business Books.

Rust, R. \&Zahorik, A. (1993). Customer satisfaction, customer retention and market share. Journal of Retailing, 69 (2): 193-215.

Schiffman LG, Kanuk LL. (2004), Consumer Behavior. 8th Ed. Pearson Education, New Delhi.

Schneider LG, Currim IS. (1991). Consumer purchase behaviours associated with active and passive deal- proneness. International Journal of Research in Marketing ;8(3):205-222.

Schultz DE, Robinson WA (1998). Sales Promotion Management.

Shammout MD, (2016). The Impact of Promotional Tools on Consumer Buying Behavior in Retail Market. International Journal of Business and Social Science, Vol. 7, No. 1; January 2016

Shimp, T.A. (2003). Advertising, Promotion, and Supplemental Aspects of Integrated Marketing Communications. 6th ed., USA: Thomson SouthWestern.

Sinha, I. and Smith, M. F. (2000) "Consumers perceptions of promotional framing of price” Psychology \& Marketing, Vol. 17, No. 3, pp. 257-75.

William M. Pride and Ferrel. (2008), Marketing, 14th edition, page 565

Zallocco, Ronald; Pullins, Ellen Bolman; Mallin, Michael L. (2009). 'A reexamination of B2B sales Performance', Journal of Business \& Industrial Marketing, vol. 24, issue 8, pp. 598-610 